\title{
Espacios y luchas femeninas. Usos y apropiaciones espaciales en la Costa Chica
}

\section{Nuria Jiménez ${ }^{1}$}

${ }^{1}$ Universidad Nacional de Educación a Distancia (UNED), España. Correo electrónico:nuria_j.g@hotmail.com

\section{Resumen}

${ }^{2}$ Tanto el nombre del pueblo como el de las personas son pseudónimos que pretenden conservar el anonimato de los y las informantes.

En este artículo me propongo hablar de cómo en San Lorenzo², Costa Chica de Oaxaca, tanto espacio como tiempo están atravesados por el género, es decir, cómo éste produce unos imaginarios espacio-temporales llenos de simbolismos, poder y significados diferenciados genéricamente. Estas diferencias posibilitan el control, a veces simbólico, de los hombres sobre el ámbito productivo. Me interesa cómo a pesar de que en la ideología existente en San Lorenzo se asignan los espacios domésticos a las mujeres, éstas se apropian de los espacios públicos y los convierten en domésticos feminizándolos a través de sus prácticas.

Palabras clave: género, espacio, dominación, resistencia, etnografía.

\begin{abstract}
In this article, based on ethnographic fieldwork, I intend to discuss how in San Lorenzo, Costa Chica of Oaxaca, so both space and time are determined by gender, i.e. how it produces space-time imaginaries full of symbolisms, power and generically distinct meanings. These differences make it possible for men to control the productive sector, through
\end{abstract} REVISTA ESTUDIOS DE GÉNERO LA VENTANA, NÚM. 44, JULIO-DICIEMBRE DE 2016, PP. 142-186, ISSN 1405-9436 
symbolic domination. I am interested in how, despite the existing ideology in Morelos that assigns women to domestic spaces in spite of the existing ideology in Morelos. They hijack public spaces and turn them into domestic ones, feminizing the spaces through their practices.

Keywords: gender, space, domination, resistance, ethnography.

RECEPCIÓN: 22 DE SEPTIEMBRE DE 2015 / ACEPTACIÓN: 03 DE MARZO DE 2016

\section{Para empezar}

Este texto forma parte de la investigación que realicé para mi tesis doctoral en Antropología Social y Cultural, la cual está en proceso de finalización y que se propone investigar las normas, la normatividad y el control social que se ejerce sobre las mujeres en una comunidad de la Costa Chica. Lo que se pretende mostrar es cómo a partir de las normas socio-culturales que establecen cómo debe ser una mujer, se van construyendo normatividades de dominación y control sobre estas. En realidad es una investigación sobre las relaciones de poder que se establecen entre mujeres y hombres y entre unas mujeres y otras. Sobre cómo a partir de ciertos conceptos, como la "necesidad", estas mujeres van construyendo resistencias a través de la ocupación de ciertos espacios y la apropiación de ciertas actividades. 
${ }^{3}$ Trabajo de campo para la elaboración de mi tesis doctoral, la cual realizo en el Departamento de Antropología Social y Cultural de la Universidad Nacional de Educación a Distancia (UNED), España.

${ }^{4}$ Este tipo de entrevista (siete) se aplicó a las principales autoridades de la comunidad (todos hombres), director de la escuela de primaria, el director y dos profesores de la escuela preparatoria, el médico, los presidentes de dos importantes asociaciones civiles de la zona, $y$ la esposa de uno de ellos que acaba de fundar una asociación por la defensa de los derechos de las mujeres.

${ }^{5}$ Las entrevistas en profundidad (seis) se realizaron principalmente a componentes de la familia con la que residía, vecinas y comadres de estos familiares, y a mujeres "importantes" en la comunidad (es decir que tanto las mujeres como los hombres de la comunidad reconocen como importantes, ya sea por su participación en las fiestas y bailes, como por ser curanderas, o participar en la política).

${ }^{6}$ Las historias de vida fue la metodología que decidí usar para recoger las voces, experiencias y pensamiento de cuatro cantineras y de dos miembros de la familia con la que residía.

${ }^{7}$ El término moreno es el más usado a nivel coloquial por las personas que viven en esta zona, nosotros somos morenos. También utilizan el término negro o negra para poner énfasis en el tema de la identidad, cuando hablan con alguien extranjero o cuando se comparan con otros grupos. Los términos "afrodescendiente" o "afromexicano" no son usados por los "costachiquenses", (ni morenos, ni indígenas ni mestizos). Son términos utilizados desde la academia, la política y por organizaciones con fines estratégicos.
Surge del trabajo de campo realizado durante el año 2010 (marzo-noviembre) y el año $2014^{3}$ (abril) en la Costa Chica de Oaxaca, en particular en una comunidad perteneciente al municipio de Jamilitepec.

Desde el inicio se optó por una metodología de investigación principalmente cualitativa, priorizando la observación participante, las entrevistas semidirigidas $^{4}$, las entrevistas en profundidad ${ }^{5}$ y las historias de vida ${ }^{6}$, considerando que los relatos de vida en primera persona son la mejor forma de expresar las experiencias, pensamientos y emociones.

Mi etnografía estuvo centrada en mujeres "morenas", en las estrategias usadas por estas para "resistir" al control patriarcal (sin una oposición directa), transgrediendo la "norma", lo cual a su vez va poco a poco constituyéndose en una "norma" fuera de la "norma". Mediante estos mecanismos de "encauzamiento social" las mujeres encuentran espacios de poder y estrategias de resistencia para garantizar su supervivencia.

Desde mi llegada a la comunidad de San Lorenzo, comuniqué el objetivo de estar allí, en un principio a la familia con la que residía y a las autoridades de la comunidad, y más tarde a las perso- 
nas con las que interactué, convirtiéndose muchas de ellas en informantes clave.

Necesario para conocer y comprender las trayectorias y rutinas diarias de las mujeres, fue el compartir con ellas las actividades, los espacios y los tiempos. Este proceso requiere de una estancia prolongada en campo y caracteriza al método etnográfico. Esta metodología es necesaria para generar relaciones de confianza que permitirán el acercamiento a comportamientos cotidianos, a comentarios más privados y relaciones mucho más íntimas.

El ser mujer me permitió estar presente en prácticamente todos los ámbitos y espacios ocupados por las mujeres, lo cual hizo que se establecieran algunas relaciones de gran confianza y cercanía. Esta presencia en ámbitos cotidianos familiares y, de alguna manera, bastante privados, ayudó a la recolección de datos muy ricos y esclarecedores sobre las relaciones de género, el papel que ocupan las mujeres socialmente y cómo piensan y sienten ellas respecto a otras mujeres y respecto a los hombres.

También participé en el trabajo de recogida, lavado, envoltura y colocación de la papaya, lo cual me permitió estar presente en un espacio y una actividad bastante masculinizada, algo que de otro modo hubiese sido bastante difícil.

Los rituales a los que asistí, tanto civiles, (cumpleaños, clausuras), como religiosos, (día del santo patrón, bautizos, etcétera), muy abundantes en San Lorenzo, fueron espacios privilegiados para hacer etnografía ${ }^{8}$.

\begin{abstract}
${ }^{8}$ Me gustaría apuntar que tras llevar unos meses en la comunidad, comencé a darme cuenta que tanto la libertad, como el control de las mujeres dependía mucho, primero, del tipo de relación afectiva-amorosa que tuvieran con los hombres y sobre todo del lugar que ocuparan en el ciclo vital. Por tanto decidí hacer una clasificación que tuviera en cuenta el primer aspecto (mujeres casadas, fracasadas, queridas y solteras) y también el segundo (niñas,
\end{abstract}


adolescentes, jóvenes casadas, señoras, ancianas).

Estos dos aspectos van a ser fundamentales a la hora de juzgar los buenos o malos comportamientos, en el momento de realizar un juicio sobre alguien por desobedecer las normas, tener la libertad de ocupar unos espacios u otros, etcétera. En la comunidad una adolescente (se es niña hasta los diez, doce años) pasa a ser mujer casada entre los quince y los diecisiete años, cuando se huye a vivir con su novio a casa de los padres de éste. Entre los cuarenta y cincuenta se las considera ya señoras, ya que se acercan a la menopausia y la mayoría son abuelas. Una mujer a partir de los sesenta años es considerada anciana, vieja como dicen en San Lorenzo; ya está vieja, dicen.

\section{En un lugar de la Costa Chica...}

La Costa Chica es una extensión litoral del pacífico mexicano que comprende la franja costera que va desde Acapulco, en el estado de Guerrero a Santa María Huatulco, en el estado de Oaxaca.

Anterior a los años 60, la región se encontraba aislada del resto del país por carecer de vías de comunicación. No fue hasta el año de 1966, con la construcción de la carretera que va desde Acapulco y recorre la costa de Guerrero y Oaxaca, que las distintas localidades de la región se fueron integrando paulatinamente a la economía nacional.

Actualmente, las actividades económicas de la región se concentran en el sector primario, entre las que podemos mencionar a la ganadería, actividad asociada con el legado colonial de la charrería y las haciendas, mismas donde se concentraron grupos de africanos y sus descendientes. También la agricultura ha tomado un lugar importante en la producción regional, podemos señalar como principales productos, el maíz, ajonjolí, jamaica, cacahuate, limón, plátano y principalmente la papaya, cuyo cultivo ha ido desplazando al de los demás productos. Cabe mencionar que el cultivo de limón, de plátano y de papaya es para la comercialización a nivel nacional e internacional. También las actividades como la copra y la pesca intervienen en la dinámica económica de la región (Miranda, 2012: 69). 
San Lorenzo es la localidad donde realicé mi trabajo de campo. Es una de las más importantes del municipio llamado Santa María Huazolotitlán, que a su vez pertenece al Distrito de Jamiltepec, ubicado en la región de la Costa, de Oaxaca, junto con los distritos de Pochutla y Juquila.

San Lorenzo forma parte de una zona con una historia caracterizada por encuentros y desencuentros, préstamos e intercambios culturales, desplazamientos y ocupaciones. Su población es principalmente "morena", como se autodenominan ellos, pero también hay algunas familias mestizas (las de mayor capital económico en la comunidad) y algunas familias de origen mixteco (cada vez hay más que llegan a San Lorenzo buscando trabajar en la recolección de papaya). Es un área habitada por grupos culturalmente diversos, aunque relacionados, que históricamente han compartido y competido por las tierras y los recursos.

La principal fuente de ingresos de la población se adquiere a través de la agricultura que representa el 50\% de la actividad económica que se desarrolla en la región, la ganadería, que supone un $40 \%$ y el comercio, que ocuparía el restante $10 \%$. La mayoría de la población masculina (también trabajan algunas mujeres pero las menos) de la localidad trabaja en el "campo". Desde hace unos años se fue sustituyendo el cultivo de limón, ajonjolí y otros productos por el de papaya (destinado al comercio exterior). Esta intensificación en el monocultivo también fue acompañado de una menor presencia de las mujeres en el campo, ya que hace unos 
${ }^{9}$ Todos los testimonios estarán en cursivas. veinte años las mujeres todavía iban al campo y según ellas trabajaban "como puro hombre".

Habiendo sido una zona, la de la Costa Chica poco estudiada y su población bastante invisibilizada (a nivel histórico, político, económico y cultural), es a partir de los estudios de Aguirre Beltrán que se comienza a prestar atención a esta población. En la actualidad son numerosos los estudios que se han hecho sobre diferentes aspectos, principalmente culturales y políticos (sobre el papel de las asociaciones o sobre la identidad y el reconocimiento), de la población "afromexicana". A pesar de esto aún son escasos los trabajos que tratan el tema de género (en la Costa Chica), y prácticamente inexistentes los que analizan la importancia de las mujeres en las estrategias de supervivencia cotidiana y en la apropiación y feminización de los espacios como parte de estas estrategias.

Las mujeres de las que vamos a hablar, desarrollan estrategias con las cuales neutralizan el control que ejercen los hombres sobre su potencial productivo y reproductivo. Estas estrategias se llevan a cabo gracias a la existencia y constante creación de redes femeninas y a su presencia en prácticamente todos los espacios comunitarios. Gracias a estos vínculos femeninos y a estas presencias, las mujeres se aseguran apoyos múltiples a través de los cuales hacen frente a la inestabilidad conyugal y económica. Esto genera algo similar a lo que Rosío Córdova denomina "equilibrio de poder", el cual en el caso de San Lorenzo, está en constante negociación. Al respecto nos dice la autora: 
este cambiante 'equilibrio de poder' entre los géneros, en sus variantes de subordinación, resistencia, alianza y redes de solidaridad debe ser estudiado en la dinámica que presentan sus modalidades concretas, ya que es en el ámbito colectivo donde se manifiestan las continuidades marcadas por la tradición y los elementos que prefiguran las transformaciones (Córdova, 2003: 47).

\section{Transitando de lo privado a lo público,} de lo reproductivo a lo productivo

El espacio es donde se actualizan y ponen en juego las nociones culturales de género, que se concretan en actividades, prácticas y conductas realizadas cotidianamente, que están estrechamente ligadas con una concepción del mundo y con la construcción subjetiva del sujeto. El género entonces se erigirá como elemento relevante en la producción de imaginarios geográficos imbuidos de simbolismos, poder y significados donde es posible localizar a uno y otro género (Soto Villagrán, 2003: 88).

Efectivamente desde que somos pequeños, mujeres y hombres vamos aprendiendo a relacionarnos con el espacio de forma diferente. Las mujeres han sido históricamente relacionadas con el espacio privado y doméstico y los hombres con el público y político.

Nos dice Teresita de Barbieri que: 
En términos generales, las feministas y las (os) estudiosas(os) de la condición de las mujeres identificamos el espacio público como el lugar de trabajo que genera ingresos, la acción colectiva, el poder, es decir, el lugar donde se produce y transcurre la historia, y el mundo privado como el de lo doméstico, del trabajo no remunerado ni reconocido como tal, las relaciones familiares y parentales, los afectos, la vida cotidiana. El primero, masculino; el segundo, femenino (De Barbieri, 1991: 203).

Esta relación del mundo privado con lo doméstico y a su vez con el trabajo no remunerado surgió con el auge de la modernidad y el afianzamiento de la sociedad burguesa, y fue una de las principales herramientas para la domesticación de la mujer, al atribuirle también a ella la vigilancia tanto del propio cuerpo como el de sus hijos y por supuesto de la higiene, el orden y la imagen del espacio doméstico, siendo este una continuación de su propio cuerpo. Pero

${ }^{10}$ Este tema ya ha sido discutido por autoras feministas como bell hooks, la cual criticó la visión racista y clasista; la argumentación de Betty Friedan en su obra La Mística de la Feminidad, cuando esta defendía y reivindicaba la liberación de las mujeres del trabajo doméstico para profesionalizarse como hacían los hombres blancos. Dice hooks que Friedan no considera a las mujeres afrodescendientes, y añadiría yo ni a las blancas pobres, que siempre trabajaron en las calles y en la casa de los y las blancas, como herencia de la esclavitud y de la escasez económica (hooks, 2004). esto sólo se lo podían permitir un grupo de personas, en los hogares populares las mujeres no podían quedarse tan sólo en el ámbito doméstico ${ }^{10}$, tenían que salir a comprar, a traer agua y muchas otras actividades que se realizaban en el espacio público. Además de que muchas mujeres se dedicaban a la venta callejera para aportar a la manutención masculina, o para mantener a sus familias siendo mujeres solteras, viudas o separadas (lo que en la 
comunidad serán las mujeres fracasadas $\left.{ }^{11}\right)$. ¿Qué

${ }^{11}$ Este término se refiere a las mujeres que tienen relaciones sexuales con hombres, quedando normalmente embaraocurría con esas mujeres? Volveré a este tema más adelante cuando describa las actividades de las zadas y luego o se separan por propia

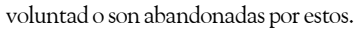
mujeres en San Lorenzo y su apropiación del espacio público.

Como nos dice Soto Villagrán, la antropología ha trabajado mucho la distribución diferenciada del espacio y los comportamientos que tanto hombres como mujeres adoptan en uno u otro espacio. Desde el feminismo también se ha trabajado mucho la asignación jerárquica de espacios a hombres y mujeres y se ha defendido que esto tiene como objetivo el mantenimiento del orden social y la dominación de las mujeres. Nos dice Olivia Harris que con el capitalismo la esfera doméstica se convierte en un ámbito separado y privatizado, lo cual facilita el control de las mujeres, por un lado y se le da un carácter natural, lo cual asegura la subordinación de estas mujeres, por otro (1986: 218).

Esta división entre dentro y fuera del hogar, está acompañada del reconocimiento de las actividades masculinas como "actividades productivas" y las femeninas como "actividades reproductivas", siendo estas últimas las menos valoradas y consideradas como menos importantes. Al respecto nos dice Henrietta Moore que: "Si el trabajo se entiende normalmente como trabajo remunerado fuera del hogar, entonces las labores domésticas y de subsistencia desempeñadas por la mujer quedan infravaloradas" (Moore, 1999: 60). Pero las mujeres también se ocupan de actividades productivas que no sólo no son reconocidas sino que además se invisibilizan. En este sentido habría que prestarle atención a cómo el colonialismo y el 
capitalismo impactaron y reestructuraron las economías tradicionales, propiciando esta invisibilidad.

La clara separación que existe teóricamente entre público y privado, productivo y reproductivo no se da en la práctica, corresponde a un ideal, lo cual no quiere decir que no sean categorías muy útiles para analizar las herramientas de dominación y domesticación de las mujeres.

En la práctica cotidiana esta división es más confusa. Los espacios responden a temporalidades, es decir, hay momentos del día en que las mujeres se apropian de los espacios públicos y los feminizan y a la inversa, en todos los lugares hay mujeres que se ocupan de actividades productivas dentro y fuera del hogar (Moore, 1999: 60).

Que la línea divisoria sea confusa no quiere decir que el "ideal", el discurso que pretende normativizar y los mecanismos que pretenden mantener esta normatividad, no busquen la separación de espacios y el respeto de esta división público y privado. De hecho como veremos más tarde, durante los primeros años de matrimonio las mujeres de la comunidad estarán sometidas a esta ideología de dominación y control, tanto de sus cuerpos, como de su sexualidad, de tal forma que apenas podrán salir solas de casa, en muy raras ocasiones se las permitirá trabajar y si van a comprar o a visitar a alguien les acompañará su suegra o algún miembro de la familia de su marido.

Pero en la práctica cotidiana esto es un camino de tránsito, en el que las condiciones socio económicas hacen que se tenga que negociar cómo y cuándo se está en cada lado o si, incluso, hay momentos en los que se puede estar en medio. 
Este continuo transitar de lo público a lo privado (doméstico), del trabajo reproductivo al trabajo productivo, es lo que me propongo explicar a través del uso de los espacios y los tiempos por hombres y mujeres en San Lorenzo. Cómo, son las mujeres "solas", que no viven con un hombre (ya sea porque están solteras, fracasadas o son queridas), las que, movidas en un principio por la "necesidad", harán este tránsito, ocupando y sintiéndose cómodas en ambos ámbitos (privado, público, productivo y reproductivo):

Se puede entonces plantear que son los requerimientos que se dan en la experiencia concreta y vivida de pobreza y precariedad cotidianas lo que hace que se transgredan algunas normas. Y esto, a su vez, 'crea norma' a través de esa misma experiencia concreta vivida por cada uno [...]. Es la experiencia de pobreza — vivida como 'la necesidad' — la que nos puede servir de elemento analítico que explique los comportamientos que aparentemente disienten de unas normas a las que sin embargo sus actores se sienten ideológicamente apegados (Bastos, 2000: 422-23).

\section{Espacios femeninos, hombres que estorban}

Me gustaría comenzar describiendo el día a día para así presentar una imagen clara de cómo es el uso de los tiempos y espacios en la vida cotidiana. 
En la comunidad los espacios (así como los tiempos de uso de esos espacios, añadiría yo) son muy importantes, como dice Cristina Masferrer, en la construcción de un sentido de lugar y pertenencia, a partir de los lugares donde se da la convivencia, la reunión y la socialización, ya que es en estos donde se crean y refuerzan las redes sociales, familiares y religiosas (Masferrer, 2014: 134).

\section{Comenzando el día}

El día para la mayoría de los hombres comienza a las seis de la mañana. Se visten, desayunan y esperan a que les pasen a recoger

${ }^{12}$ Con mujer me refiero a "compañera" o "esposa". Utilizaré indistintamente las tres categorías ya que en el contexto de la comunidad significan lo mismo. La mayoría de las parejas viven juntas pero no se han casado legalmente. Muchas incluso pasan la mayoría de la vida sin casarse, haciéndolo ya de ancianos, en bodas colectivas, que suelen ser gratuitas. Como dice Víctor Franco, "[...] el estado matrimonial no es considerado existente solamente en cuanto se encuentre legitimado por un código civil o religioso, sino en tanto tenga una legitimación basada en el reconocimiento social" (1992: 17).

A lo largo del texto me referiré a mujer "sola" para referirme a las mujeres que por ser "fracasadas", o solteras o queridas, no tienen un compañero con el que viven y comparten la unidad doméstica, los gastos, los deberes y obligaciones, tal como lo hacen las parejas que están "casadas" (ya sea legal o socialmente). el patrón para llevarles al papayal a trabajar. La mujer ${ }^{12}$ suele levantarse antes que el hombre y aprovecha para ir a moler el maíz al molino. Mientras su marido se viste y espera al patrón, ella le prepara las tortillas que se llevará para almorzar y algo para echarle a las tortillas (chile, frijol, chorizo, huevo). Los chicos jóvenes tanto casados como solteros llevan a cabo el mismo ritual, con la diferencia de que si no están casados, el desayuno y el almuerzo se lo preparará su madre. Los ancianos, como ya no van a trabajar al campo como asalariados, normalmente salen de casa al amanecer para trabajar en su terrenito (la mayoría tienen pequeñas milpas donde siembran su maíz, ajonjolí, limón, algún palo de mango, etcétera), limpiar el terreno y recoger zacate 
para darle de comer al ganado o a los caballos ${ }^{13}$. Estos hombres (los ancianos) suelen estar de vuelta en la casa a media mañana donde permanecerán prácticamente todo el día. Algunos vuelven a sus terrenos al atardecer pero esta vez estarán fuera menos tiempo que en las mañanas.

Los hombres que salieron al campo (hay quienes trabajan en la construcción o en otros servicios, pero son los menos) a trabajar en la mañana, regresan a partir de las cinco de la tarde. Los camiones que traen a los jornaleros que regresan de los campos de papaya, entran en el pueblo por la clínica y van dejando a cada uno en su casa. Normalmente lo primero que hacen es bañarse, jugar con los hijos pequeños (si es que los tienen) y tumbarse en la hamaca a descansar, a ver la novela o a charlar con vecinos o familiares. No obstante, los hombres adultos apenas pasan tiempo, de lunes a sábado, en las unidades domésticas. El sábado, la jornada laboral termina antes, como a las dos o tres, además se cobra la raya, que es el sueldo semanal, por lo que muchas veces los hombres se van directamente con los amigos a las cantinas o a una tienda ${ }^{14}$ en la que se vende alcohol. Lo habitual y esperado el fin de semana será ver a los hombres siempre cerca de cantinas y lugares donde se venda alcohol o del campo de futbol los días que hay partido. En definitiva, los hombres no suelen estar muy cómodos pasando
${ }^{13}$ Esta zona históricamente se convirtió en lugar de grandes haciendas ganaderas donde la población morena era "utilizada" por los españoles como capataces y guardianes del ganado, siendo muy diestros a lomos de un caballo. Esto se ha mantenido y desde bien jóvenes se habitúan a andar en caballo. 


\footnotetext{
${ }^{15}$ Excepto los ancianos, los cuales suelen compartir mucho tiempo y espacio con sus esposas y familiares. Es ya a partir de que los matrimonios se convierten en abuelos, que los espacios de unos y otras se difuminan, unos se feminizan y las otras se masculinizan, llegando a una cierta "igualdad".
}

mucho tiempo en el espacio doméstico ${ }^{15}$, por eso muchos dicen que se aburren cuando no tienen que trabajar. La mayoría del tiempo, exceptuando cuando regresan a sus casas en la tarde-noche, los hombres, lo pasan en espacios masculinos o masculinizados con su presencia (como el campo, cantina o la cancha), esto responde a cómo se construye y ejerce la masculinidad en ciertos espacios. Como dice Mara Viveros:

Una dimensión importante de la masculinidad es su expresión en los espacios públicos, espacios simbólicos del poder, del que las mujeres no han formado parte tradicionalmente [...] en el mundo contemporáneo [...] una parte de los varones transcurre en lugares monosexuados, es decir en espacios cuyo uso o presencia se le atribuye en forma casi exclusiva (2002: 98-99).

El domingo normalmente en las casas es día de reunión femenina, mientras el o los hombres pasan la cruda en la hamaca a base de agua, coca-cola y bañándose cada cinco minutos, las mujeres se reúnen en casa de una familiar, charlan, pasan la tarde contando los "chismes", comentando lo que ha ocurrido durante la semana. Durante mi estancia en "Lorenzo" fueron constantes los chismes como forma de relato, es decir yo fui conociendo a la gente de la comunidad a partir de los chismes que constantemente eran elaborados sobre unas y otros. Pero a partir del chisme podemos darnos 


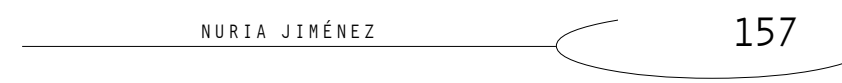

cuenta de las normas de conducta (genéricas) que deben seguir en este caso las mujeres y cuáles no son aceptadas socialmente y por tanto castigadas. El chisme nos:

Permite reconocer, cuestionar y reafirmar, según sea el caso, las reglas sociales de convivencia, exclusión, rechazo o aceptación y, además, como elemento que sugiere un ejercicio de poder a partir de la competencia lingüística por parte de quien lo genera o inicia (Chávez, Vázquez y De la Rosa, 2007: 27).

Las mujeres como ya decía antes se suelen levantar antes que los hombres, ya que deben ir al molino a moler el maíz para hacer las tortillas, es normal ver sobre las seis o siete de la mañana a las mujeres andando dirección al molino, allí se encuentran y conversan mientras unas y otras van moliendo su masa. Después de eso cada una vuelve a su cocina ${ }^{16}$, que está normalmente fuera de la casa —al tener el comal para hacer las tortillas, necesita una ventilación especial porque el humo debe salir por paredes y techo- $\mathrm{y}$ se ponen a elaborar las tortillas con las demás mujeres de la casa. Es tan importante este espacio femenino común, que la construcción ${ }^{16}$ En las unidades habitacionales lo nor-
mal es que haya una cocina comparti-
da por todas las mujeres que viven en
ella. Este sería el espacio que gestiona-
ría las relaciones de consumo en los
hogares. Y por tanto estas mujeres se-
rían las gestionadoras, lo cual no signi-
fica que ellas controlen este consumo,
ya que el control, normalmente está en
manos de los varones. Excepto en el caso
de las mujeres solas (la mayoría madres),
en el que estos recursos sí serían direc-
tamente controlados y distribuidos por
ellas. de una cocina aparte o la compra de una estufa por parte de alguna mujer del grupo doméstico es un mensaje claro y contundente de independencia y de alejamiento del resto de las mujeres, algo que en ocasiones puede ser malinterpretado. 
Es un tiempo y un espacio de y para las mujeres, el que dedican a ir a moler y luego a tortillear. Las mujeres se reúnen, muchas veces con motivo de una celebración, a hacer tortillas, charlar, comer, hacer bromas, etc. Mientras ellas están en la cocina es muy raro que algún hombre entre; pasará cerca, saludará o se quedará fuera hablando, pero en seguida seguirá su camino. En las cocinas se pueden juntar todas las generaciones de mujeres, desde las chamacas hasta las mujeres ancianas.

Aunque ya hay dos tortillerías en el pueblo, la mayoría de las mujeres sigue prefiriendo hacer ellas mismas las tortillas. Además muchos hombres se niegan a comer las tortillas de la tortillería. El hacer tortillas es un rasgo muy importante que define a la mujer en la costa, al igual que en la mayoría de comunidades indígenas. Desde bien pequeñas las niñas (algo que les comenzará a molestar cuando lleguen a la adolescencia y se les pida ayuda para esta tarea) aprenden a hacer la bola de maíz, a aplastarla con la mano dándole forma redondeada y a colocarla en el comal sin que se rompa. Así mientras sus madres, tías y abuelas van haciendo las tortillas, ellas se sitúan a un lado para ver los pasos que deben seguir y comienzan a imitarlas, esperando el momento de llegar a ser una de ellas. Este momento no llegará hasta que se huyan, es decir cuando tengan marido y pasen a ser mujeres adultas pudiendo participar en la elaboración de tortillas junto a las demás mujeres, en eventos, y festejos. Dora, una de las mujeres con las que vivía, me contaba cómo las chamacas aprenden desde niñas por 
estar de chismosas en la cocina con las mujeres adultas, madres, tías y abuelas:

Mírala ya se siente mujer, quiere estar chismoseando lo de las mayores.

Una mujer que no hace tortillas no será muy bien valorada:

[...] es bien floja, no le gusta ni tortillear y ahora pura tortilla de tortillería. Es una mujer que nunca le ha gustado hacer oficio (Dora).

Culturalmente el hacer tortillas es una obligación de la mujer y se da por sentado, no se discute. Por lo tanto también puede ser utilizado como "arma" de protesta o resistencia, es decir la negación a cocinar, a mantener relaciones sexuales o a hacer oficio pueden ser manifestaciones de resistencia frente a los maridos. Es una clase de resistencia cotidiana femenina (Moore, 1999: 213).

Durante la mañana, suelen pasar por las unidades habitacionales numerosas personas, desde los chicos que venden el agua, hombres que pasan por parcelas vecinas para acortar camino, mujeres que van o vienen a comprar, que llevan a los niños al kínder o vendedoras de verduras, frutas, pescados, panes, ropa, etc.

Lo que me interesa de esto es la interacción entre mujeres, tanto si son vecinas, familiares, como si son vendedoras, lo habitual es que lleguen y se sienten a charlar un rato. Si son vendedoras gritarán desde el camino por si alguna mujer quiere comprar algo, otras llegan hasta las puertas de las casas y lo habitual es que se les facilite 
una silla para que se sienten (no es muy habitual llegar a casa de alguien y charlar estando de pie, lo primero que hacen las personas de la casa es ofrecer una silla). Se las pregunta si quieren algo de beber y comienza la conversación, convirtiéndose, a veces, en verdaderos repasos por las novedades de la comunidad (chismes).

Todas estas formas de interacción también contribuyen a afianzar las redes sociales, basadas en vecindad, amistad y parentesco. Estas redes son indispensables para la circulación de servicios, bienes materiales e información (dentro de la lógica de comunidad y reciprocidad), siendo estos indispensables en contextos de escasez económica: "En un contexto de recursos escasos al parecer no existen opciones para controlar y distribuir los recursos de forma privada" (Narotzky, 2004: 200).

\section{Ocupando todos los espacios}

Durante el día el pueblo es bastante bullicioso, lo habitual es encontrarse a mujeres que van a comprar, hablando en las calles, unas fuera de las casas de otras, conversando, gritándose de una calle a otra, riéndose a carcajadas y bromeando con sus comadres y sus compadres, con los que comparten el carácter escandaloso. También es habitual que durante el día, cuando los hombres están trabajando, se vaya a visitar a las hermanas, tías, madres o abuelas.

La clínica también es un lugar de presencia femenina, primero porque el personal médico es mayoritariamente femenino, siendo el doctor el único hombre y segundo porque lo hombres apenas 
acuden a la clínica. Las tres cuartas partes de las personas que acuden a la clínica son mujeres, van tanto para sus padecimientos como para los de sus hijos (incluso para los de sus maridos y padres):

Las mujeres son las que más vienen a consulta, la mera verdad... será por el programa que tienen de Oportunidades, no sé... Los señores que si no quieren perder tiempo... no acuden casi por sus padecimientos. Los señores se automedican, una o dos pastillas y ya se van a trabajar (Doctor).

La mayoría de las tienditas que hay en el pueblo son atendidas por mujeres. Si una va a la Municipalidad será recibida y atendida por la secretaria del agente municipal. Incluso en las cantinas, durante el día, sólo hay mujeres. Puede que haya algún o algunos hombres que no fueron a trabajar o que no trabajan ya, pero normalmente si se visita una cantina entre semana y durante el día, tan sólo se encontrará a la dueña de la cantina y las chicas que trabajan en ella (de estas mujeres hablaremos al final del artículo).

También se pueden encontrar grupos de mujeres alrededor de la escuela, ya que son las que llevan a sus hijos. Algunas regresan a la hora de comer para llevarles la comida y a recogerles y a veces se esperan charlando con amigas desde el descanso hasta que salen sus hijos, para no estar yendo y viniendo.

Muchas mujeres, además de esta rutina diaria, hacen tamales, pozole y otros platillos para vender y ganarse su dinero, hacen su 
lucha (es como le dicen en San Lorenzo a "buscarse la vida"), quien no lava y plancha ajeno, sale a vender verduras o cocina y vende

${ }^{17}$ Son aguas de sabores, también pueden ser con leche, que meten en unas bolsitas que luego congelan. Son muy dulces y refrescantes y gustan mucho. enchiladas, tamales y los platillos que comemos acá. Dora vende quesos, carne enchilada, chorizo, bolis ${ }^{17}$. La hermana pequeña de Dora, Isabel, vende tamales verdes, de rajas y de chileajo. Todo esto significa mucho trabajo, ya que las que se dedican al pequeño comercio y trabajan fuera de la casa no están exentas de todo el trabajo dentro de esta. Del mismo modo las que venden en la casa deben compaginar las labores domésticas consideradas como actividades reproductoras con las productivas. A este respecto Moore dice que: "[...] Ha puesto al alcance de la mujer una fuente adicional de ingresos sin salir de casa y sin alterar la división sexual del trabajo ni la naturaleza de género" (Moore, 1999: 110), por otro lado nos dice MacGaffey, que este tipo de actividad paralela, invisible de algún modo y no registrada legalmente, suponen un escape al control masculino (MacGaffey, 1986: 171). Según mis observaciones y datos recogidos, en la Costa Chica este tipo de actividades constituirían para las mujeres un "escape" del control masculino, en cuanto que les hace tener una autosuficiencia y autonomía económica, pero como dice Moore, sin alterar la división sexual del trabajo. Aunque es muy importante tener en cuenta que el poder realizar estas actividades en el ámbito doméstico les facilita, a estas mujeres, el cumplimiento con todas "sus obligaciones" de género. Ya que si no pudieran compaginarlo, seguramente tendrían que 
abandonar las actividades remuneradas (productivas), aunque la economía familiar se viera afectada.

En el libro de Narotzky se citan varios estudios en los que se demuestran cómo el empleo de las mujeres se basa en el supuesto de que estas son trabajadoras subsidiarias, ya que su tarea principal es otra (trabajo doméstico) y a que no se espera que su ingreso reproduzca la fuerza laboral, sino que constituye un mero "complemento" de un "salario familiar" íntegro y masculino (Narotzky, 2004: 225). Lo cual, como veremos más adelante, no siempre es así. El aporte del marido puede desaparecer unas horas después de ser cobrado, en gastos no familiares, siendo el aporte económico de las mujeres el que solucione los gastos básicos-familiares. En el caso de las mujeres "solas" es todavía más importante, su trabajo debe ser el que las mantenga tanto a ellas como a sus hijos y otros familiares dependientes de ella, por tanto no se considera un mero complemento.

Las generaciones más jóvenes (adolescentes) trabajan en el ámbito doméstico bastante menos que sus madres o abuelas. Las madres y abuelas alegan que las nuevas generaciones: son flojas, no les gusta trabajar, sólo estar en la calle y mover el culo... iahh eso sí!. Las chicas jóvenes hacen un mayor uso de la calle, aprovechan cualquier excusa (comprar, pagar o recoger algo) que hay que hacer para ir ellas y así pasar a visitar a alguna amiga que las acompañe al centro, donde seguramente se encuentren con algún muchacho y se queden bromeando con él. La chicas adolescentes que no están huidas, es decir que no tienen marido son cuestionadas continua- 
mente, por pasar demasiado tiempo en la calle, (sobre todo si ya ha oscurecido), por hablar con muchachos que no son del pueblo, por cómo se visten, por si van muy maquilladas, si se meten en una pelea, etc. Están sometidas a un gran control familiar, ya que los chismes o cuestionamientos hacia su persona y comportamiento esconderán un juicio de valor hacia sus madres. Es decir lo que está en cuestión no es tanto el comportamiento de estas chicas sino el papel de sus madres como buenas educadoras.

Con la llegada de los hombres a las casas, todo se calma. Esto me remite a cuando Francisco Sánchez (hablando de un pueblo del sur de España) dice:

El mundo del pueblo se expande y se contrae a lo largo del ciclo del día: si los hombres salen al campo, las mujeres salen a la calle a los recados, y si los hombres vuelven del campo y salen a la calle a los bares, las mujeres se repliegan a casa, hasta el momento de máxima contracción del pueblo, por la noche, cuando todos duermen en los dormitorios, las habitaciones más interiores e íntimas de la casa (1990: 117-118).

Normalmente cuando el hombre llega a casa, está cansado y llega

${ }^{18}$ Los hombres suelen ser muy cariñosos y pasar mucho tiempo con sus hijos cuando estos son muy pequeñitos y siempre en un ambiente femenino, si están entre hombres no. A partir de los cinco o seis años que los niños comienzan a moverse con más independencia, el trato con el padre será cada vez menor (sobre todo con los varones). a que lo atiendan, es decir se dará un baño y se irá directamente a la hamaca. Desde la hamaca jugará con sus hijos ${ }^{18}$, conversará con la familia mientras ven la telenovela o las noticias, sentado fuera de su casa, en el porche, descansando, mientras 
esperan la cena. Los más jóvenes (solteros), llegan a sus casas se bañan y salen a la calle con sus amigos.

$\mathrm{Al}$ ponerse el sol, se ve menos gente por las calles, hay menos trasiego de unos y otros. También coincide con que es "la hora de la novela”. En caso que el hombre necesite algo, mandará a su mujer a pedirlo (fiado) o a comprarlo, pero dejándole claro que debe tardar poco, es decir que no se debe entretener por el camino. Debe ir y regresar rápido. No está bien visto que una mujer (sobre todo si está casada) ande por la calle, sola, de noche, todavía menos si su marido está en casa. Debe ir rápido a por el encargo y volver a la casa. No deben llegar comentarios de que la vieron pararse para hablar con uno o con otro. La mamá de Toña (informante clave) me dijo que ella no quería problemas y que por eso no tenía apenas amigas y menos amigos, que a ella no le gustaba ir de casa en casa: "Platicando con unos y con otros, ni pararse a hablar con algún hombre, porque luego ya andan diciendo que si me vieron con fulano o mengano. Yo directita pa mi casa, acá se me puede encontrar quien me busque"

Siempre se castigará más a una mujer callejera que a un hombre demasiado casero: "La severidad con la que se reprueba a la mujer callejera es mucho más rigurosa que la que se dirige al hombre casero que, fuera de las horas de trabajo, gusta quedarse en casa" (Sánchez Pérez, 1990: 76).

Pero esto es algo que está bastante asumido y cada cual tiene su lugar, su espacio y su tiempo, como ya decía antes. Y a las mujeres hasta les perturba que el hombre ande mucho en casa, porque di- 
cen que les molesta, que estorba y no hace nada. Muchas veces me dijeron que preferían que estuviese trabajando o en la calle. El hombre tampoco disfruta mucho de su tiempo libre, me decían: ya quiero que sea lunes para chambear, yo los domingos me aburro, no encuentro qué hacerle. Como dice Sánchez Pérez:

Sobrepasar en exceso los límites espacio-temporales establecidos, siempre y cuando no sea mayor o esté enfermo, comporta una trasgresión de los patrones de conducta territorial. No debe ser, pues, que el varón pase más o menos tiempo en su casa lo que le hace infringir las pautas territoriales, sino el que permanezca en el mismo espacio que la mujer (Sánchez Pérez, 1990: 56).

No significa que la mujer debe estar en la casa y el hombre en la calle, sino que la presencia demasiado larga del hombre en el espacio feminizado y apropiado por la mujer se considera una intromisión, tanto por unas como por otros.

\section{"Cómo hacerle sin un hombre"}

Como ya decíamos antes, se asume que el hombre debe ser el proveedor económico, el que aporte el monto que mantendrá a la unidad familiar y de esta asunción nace la frase cómo hacerle sin un hombre, cómo le haríamos sin ellos, me decían, son los que traen el dinero a la casa. Pero después de pasar un tiempo en la comunidad 
comencé a darme cuenta de la cantidad de mujeres que sacaban adelante a sus familias, que hacen su lucha, unas porque no tienen pareja y otras porque sus maridos se gastan lo que ganan en las cantinas o en "sexoservidoras" o en sus queridas. Esto forma parte de los requerimientos sociales de ser hombre, es decir el gastarse parte de su sueldo (o a veces todo, lo que provoca conflictos familiares) en lo que él quiera sin dar explicaciones.

Estas limitaciones generan una violencia simbólica que como dice Bourdieu impone una coerción instituida por medio del reconocimiento extorsionado que el dominado no puede dejar de prestar al dominante, al no disponer, para pensarlo y pensarse, más que instrumentos de conocimiento, que tiene en común con éste y que no son más que la forma incorporada de la relación de dominio (Bourdieu, 2000: 51). Este dominio se va a presentar a través de sistemas de percepciones, pensamientos y acciones constituidas en el imaginario colectivo como normales. Foucault (1992) estructurará el problema de la obediencia como un problema de normalización del discurso, es decir del control tanto de las conductas como de lo que se dice o no se dice, en definitiva, de la imposición de la verdad a través del poder, convirtiéndose, esta "verdad", en la mejor herramienta de dominación. Cuando lo que debe o no debe hacer una mujer, dónde debe estar y dónde no, el trabajo que debe hacer o el que no debe hacer, con quién debe hablar o con quién no, se constituye a través de un discurso normático, se naturaliza, se esencializa y se convierte en verdad, sin capacidad (aparente) de ser cuestionado y cambiado (siendo como dice Foucault un arma muy efectiva 
y sutil de dominación), hasta que comienza a desobedecerse por las circunstancias que sea y se comprueba que sí hay otras verdades.

Este dominio no necesita de una violencia física sino que se ejerce de modo simbólico configurando las mentes y los cuerpos en su acción cotidiana.

En teoría y como mandato social se supone que el hombre debe ser el principal proveedor de recursos económicos en la unidad doméstica. Al asignar esta obligación al hombre, éste deja el resto de tareas asociadas a la reproducción cotidiana a la mujer que será, por tanto, la encargada de "gestionar la pobreza", ya que están mejor "dotadas para enfrentarse al empobrecimiento que produce las crisis agrícolas o de tierras" (Bastos, 1997: 166; Moore, 1999: 107). Uno de estos modos de gestión es el compaginar la actividad reproductora y la productora, como veíamos antes. A parte de esto deben soportar que sus maridos a veces las descalifiquen por trabajar fuera del espacio doméstico (incluso cuando el aporte económico del marido no es suficiente para la manutención familiar), ya que se está rompiendo con un orden simbólico en el que cada género debe satisfacer un rol genérico (en este caso el de proveedor le correspondería al hombre).

La presión social y familiar que se ejerce sobre las mujeres cuando estas se salen de los espacios y roles en los que habitualmente se desenvuelven y que implican cierto grado de violencia, imposibilita que tanto ellas como sus familias puedan tener acceso a mejores condiciones económicas origina- 


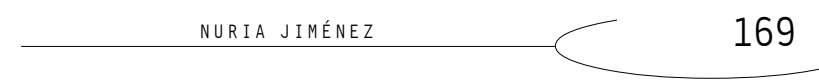

das de los trabajos y esfuerzos femeninos

${ }^{19}$ Usaré el término "Diagnóstico" para referirme a las citas sacadas del (Diagnóstico ${ }^{19}$, 2001: 174). texto:"Diagnóstico de la situación de las mujeres afrodescendientes en la Costa Chica" (ver en bibliografía).

Me comentaba Carlos (informante clave en el trabajo de campo) al respecto:

iLos maridos no las dejan trabajar! no quieren los maridos, son... no por machismo ieh! no es machismo eh, pero también es la ley de... todo, como todo pues, el hombre en el trabajo... ies la costumbre que así es pues! (Carlos).

Me decía que el marido gana el dinero y que le da a la mujer lo que él cree conveniente. Pero que si se va a beber y se gasta la raya:

¡Pues la mujer se enoja, se molesta! Hay mujeres que cuando el marido se chupa el dinero pues no le da de comer, ni de lavar ni nada... ipero mejor no enojarse porque hasta las pegan sus maridos!

i [...] y es por eso que siempre las mujeres están endeudadas! que pa cobrarte de zapatos, que pa cobrarte de esto, de lo otro! iPorque el marido no la deja trabajar!

$\mathrm{Y}$ las que salen adelante son las que tienen negocio, las que no les importa lo que piense el marido... quieren trabajar $\mathrm{y}$ tener dinero aunque sea no sea para ellas, iaunque sea para sus hijos! Porque cuando ya tienen hijos, pues ya. $\mathrm{iO}$ que sus maridos sean profesionistas o bien pagados! 
Es por esto que durante los primeros años de matrimonio muy pocas mujeres trabajan fuera de casa, apenas salen de estas, si no es con la suegra o a ver a su familia.

El orden masculino está tan profundamente enraizado en los cuerpos y en las mentes que no tiene necesidad de justificación. Es un perfecto acuerdo entre las estructuras sociales y las estructuras cognitivas incorporadas en el habitus (Bourdieu y Wacquant, 1992: 146; Bourdieu, 2000: 49-53).

Pero hay grietas en este habitus que permiten ver que quizá este orden masculino no sea algo natural e inamovible, como cuando los hombres viven separados de las mujeres, no pudiendo ejercer el control sobre estas directamente (aunque siempre hay recursos de control en la distancia). Sin querer, les proporcionan los símbolos y los recursos sociales con los que montar su propia sociedad, entendiendo aquí sociedad como sus propias redes de cooperación, intercambio y compañía (Rosaldo, 1979: 23).

Otro caso similar es el de Marta, tía de Carlos. El día que la conocí, estaban celebrando un cumpleaños y Marta estaba tomándose unas cervezas, recostada en una silla. A las mujeres morenas ${ }^{20}$ Asíle dicen a la nos gusta beber, ianda! tómate una fría ${ }^{20}$. Le pregunté si estaba casacerveza. da y me dijo que sí, que se había "juido" a los quince años:

Bien chamaquita estaba yo, de quince y él de dieciséis, al año siguiente nos casamos, fuimos a las dos semanas a pedir el parecer y el perdón. Me contó que la boda por lo civil es donde la novia (en el pueblo de ella) y la religiosa donde el novio (en el pueblo de él). Le pregunté que dónde estaba su marido y me dijo que en el norte, donde lleva- 
ba quince años. A pesar del tiempo que ha pasado desde que el decidió irse, ella le sigue siendo fiel:

Yo le quiero mucho, yo me enamoré mucho de mi marido, yo le espero, a mi no me importa que tenga vieja... el sí, uhhh, el anda con viejas, si!

Yo aquí salgo, hago lo que quiero, luego hay unas que tienen que pedir permiso, que no las dejan... Yo no, ahh, yo nunca, cuando estaba aquí mi esposo, el no, ese hombre no me decía. Yo le decía me voy, si quieres te traigo, si no que te vaya bien.

Yo no hago nada, mi suegra me dice, pero yo le digo, nooo, no hago nada malo, sólo me tomo mis dos o mis tres bien frías y bailo, uyyy, yo bailo mucho, pero no con hombres, puro con mujeres, yo mujer con mujer, sí, sí.

Ella se fue al norte a buscar a su marido pero no se encontró bien allí.

Yo me fui con él, él no quería, no me dejaba salir porque decía que allá le roban a uno la mujer, iy sííí es cierto! iPero no me hallaba yo! Cuando yo llegué él tenía vieja, yo duré seis meses, pero no me gustaba y le dije, ahí me voy pero si quieres mujer segura me mandas ieh! (me hace el gesto del dinero con la mano), si no, no tienes mujer segura. Y él sí, él me mandaba, que se quedara esa vieja con él, iella más vieja que yo! iYa era 
abuela! Mira yo me hice mi cerca, tengo mis tierras, mis vacas. Yo trabajo, voy al campo con mi hijo.

En este testimonio podemos ver varias cosas, como la autonomía que tienen algunas mujeres frente a otras. Como ya decía en el capítulo anterior suelen ser las mujeres "solas" las que transitan por los espacios más libremente. Marta es una mujer casada, pero su marido no está, no comparten espacios y por tanto actúa como una mujer "sola". La única persona que le sanciona es su suegra pero ella le dice que no hace nada malo. Por el contrario su marido vive con otra mujer pero también quiere seguir con su esposa, por lo que debe mantenerla económicamente, es decir en este aspecto

${ }^{21}$ Esto es un juicio de valor personal. Ella no lo piensa así, por lo menos su discurso es de desear que él vuelva, aunque luego las explicaciones de cómo vive y de sus actividades se contradicen con este deseo. Sería más que como mujer casada "debe" querer que él esté con ella, pero ya se acostumbró a vivir sin él y le gusta, mientras él le siga mandando dinero, eso sí. la situación de Marta sería una mezcla entre la de una mujer cuyo marido tiene querida, y la de una querida $a^{21}$, porque tanto el marido como la otra vieja, como dice Marta, están en otro país. Me explicaba Marta, cómo el marido tenía miedo de que fuera con él por si la robaban. Este es el mismo argumento que me daba un vecino cuando me hablaba de porque no quería que su mujer se fuera con él al norte. Los dos estaban con otras mujeres al argumentar esto, es curioso.

Se aprecia en su testimonio, cómo, para ella no es malo ir a los bailes, porque sólo baila mujer con mujer y se bebe dos o tres frías. Pero Marta habla de su libertad y autonomía, porque ya es una mujer madura, situada fuera de la etapa reproductiva, lo que marca una frontera en la vida de una mujer de San Lorenzo entre estar 
bajo control, tener que dar explicaciones, ser criticada o estar bajo vigilancia de mujeres mayores y tomar en cierta forma las riendas de su vida y tener un poder basado en la experiencia que permite aconsejar y criticar a otras mujeres más jóvenes.

He intentado, a partir de la descripción de las actividades cotidianas mostrar cómo se feminiza tanto el espacio privado, en este caso la unidad doméstica-casa, como el espacio público, el pueblo, durante el día y en ausencia de los hombres. Al igual que la importancia que tienen, en los usos de los espacios y en la gestión de las prohibiciones y normativas sociales (por parte de las mujeres), la etapa de la vida en la que se esté.

\section{Mujeres que "hacen su lucha"; ocupando el espacio "productivo"}

Como ya comencé a describir antes, las mujeres comienzan el día antes que los hombres y lo suelen acabar también después que ellos. Además de todas las actividades y el trabajo realizado en el espacio doméstico (cocinar, lavar trastes, lavar ropa, vestir a hijos/as, barrer el patio, moler el maíz, cocinar para salir a vender, hacer quesos, etc.) están los trabajos realizados fuera del hogar, como comprar, salir a vender los platillos cocinados en casa, las verduras y futas recogidas en el campo, vender el pescado (algunas mujeres tienen pescado que les traen o que va a recoger de familiares que viven en la costa, que se dedican a la pesca), lavan ajeno (ropa que lavan a cambio de dinero), van a limpiar a casas de otras personas y ha- 
cen tortillas y totopos para vender. Las jóvenes (adolescentes que todavía no se han casado), aprovechan sus días feriados o vacaciones para ir a recoger papaya con algún vecino o familiar y así poder ganar un pequeño sueldo que seguramente gastarán en ropa, complementos, calzado o maquillaje. Esto ha ido cambiando, las chicas jóvenes y las recién casadas no suelen trabajar como lo hacían y hacen sus madres y abuelas: algunas mujeres de unos cuarenta o cincuenta años me decían que ellas trabajaban desde que eran pequeñas, salían a vender, si no eran nanchis, eran limones y si no ajonjolí.

Todo ha cambiado, me decían, estas mujeres (refiríendose a las jóvenes) ya han ido a la escuela, no como las mujeres de antes:

Mis papás no nos llevaban a la escuela porque teníamos que ayudarles en la casa y en el campo (María).

Las mujeres que se dedican al pequeño comercio $^{22}$, que son la ma-

${ }^{22}$ Lo habitual es que las mujeres vayan solas o acompañadas de sus hijas o nietas, las cuales les ayudan en la venta, les cuidan la mercancía, ofertan la mercancía por las casas, adquiriendo confianza y práctica en este trabajo, de igual modo las niñas se van sintiendo cada vez más seguras. yoría, van haciendo suyos determinados espacios, controlando determinadas redes, lo cual les empodera en sus prácticas. Prácticas que son de continua cooperación, lo que hace que las mujeres que generan más redes de solidaridad y colaboración mutua, tengan un mayor respaldo frente a la sociedad, que las que permanecen más en el ámbito doméstico siendo objetos de una mayor vigilancia y control: "Las mujeres llegan a la conclusión de que los beneficios de la asistencia social y los víncu- 
los dentro de las redes de parientes les proporcionan una mayor seguridad a ellas y a sus hijos" (Stack, 1975: 113). Tanto Henrietta Moore como Olivia Harris hablan de la importancia en las redes domésticas, entre hogares, las cuales son mayoritariamente redes de cooperación y solidaridad femenina, para la subsistencia, cuidado y socialización comunitaria (Moore, 1999: 84; Harris, 1981: 63). Sobre este tema también ha escrito Dolores Juliano, la cual ha trabajado las diferentes asociaciones entre mujeres, tanto familiares, como extrafamiliares, siendo estas consideradas como básicas para la supervivencia del sistema social (Alborch, 2003; Juliano, 1998). Este asociacionismo y creación de redes y alianzas femeninas, siempre ha sido considerado peligroso en la ideología patriarcal. Por tanto y respondiendo al lema "divide y vencerás", la mujer ha sido separada de las "suyas" a través de numerosas estrategias, como la "expulsión" a través de la residencia patrilocal o como el "encierro" respaldado por la ideología de la "domesticidad" (Alborch, 2003).

Este control se ejerce más en los primeros años de matrimonio, mientras la mujer tiene sus primeros hijos (el control sobre las mujeres y sus cuerpos se ejerce sobre todo en los años reproductivos, una vez pasada la menopausia, las mujeres gozan de mayor libertad y decisión sobre sus movimientos y cuerpos). En este sentido Claude Meillasoux señala que:

Menopáusica y abuela, en revancha, queda liberada de esas obligaciones y se desarrolla socialmente, adquiere una autoridad que le era negada en tanto esposa y madre. Viuda e inca- 
paz de procrear, su condición se aproxima a la del hombre a quien puede sustituir (1999: 112).

Vemos que el pequeño comercio es casi exclusivo del dominio femenino. Las mujeres son las encargadas de la economía doméstica y del intercambio: a los hombres les da pena, me decían respecto al pequeño comercio. Por tanto me parece importante analizar no sólo el valor económico del trabajo sino también el valor social. El pequeño comercio también incluye pequeñas tiendas y abarrotes familiares, las cuales suelen ser atendidos también por mujeres (hijas/ os o madres de estas). Las que no quieren llevar a sus hijas (mientras van de casa en casa vendiendo) cuentan con una gran red de solidaridad femenina basada en la unidad doméstica que es la base social y cultural organizativa de estos grupos, constituyen las redes sociales en las que se tejen las relaciones más importantes de intercambio y reciprocidad. Esto les concede a las mujeres una gran movilidad, ya que en caso de que no puedan o no quieran trasladarse con sus hijos tienen la opción de dejarlos con miembros de estas redes femeninas, gracias a la gran solidaridad colectiva con relación a los niños, así se les concede la posibilidad de intervenir con la misma autoridad que tendrían los padres: "Los niños circulan entre las mujeres de la red doméstica y articulan redes matrilaterales y patrilaterales" (Stack, 1975: 62-105).

Presento al pequeño comercio como una estrategia (que usan estas mujeres) de ocupar espacios y feminizarlos al igual que de estar presentes en la esfera productiva. Esto, a su vez les permite, a 
las mujeres, ejercer cierta resistencia a la "domesticación" y reclusión al espacio doméstico, mecanismos de control, que gracias a las nuevas formas de socialización, cada vez más individualistas, introducidas y fomentadas por las lógicas capitalistas, van reduciendo el trabajo de las mujeres en el campo y en el comercio. Las nuevas formas de familia y de residencia hacen que se privatice más la vida íntima y que la vida de las mujeres se vuelva a convertir en algo privado (llegando a ser algo peligroso para las mujeres).

La resistencia a estas estrategias, no necesariamente conscientes, se apoya principalmente en la formación y mantenimiento de redes de cooperación y solidaridad femenina.

\section{Mujeres luchonas: el espacio de la cantina}

Algo que me llamó la atención al llegar al pueblo fue que las dueñas de prácticamente todas las cantinas fueran mujeres y la mayoría mujeres "solas". En San Lorenzo todas las cantinas están junto a la casa de la dueña, suelen situarse en el mismo espacio o terreno, por lo que en realidad es una continuación del espacio doméstico y privado. Desde este punto de vista se constituiría como un espacio femenino ya que sería una prolongación de la casa de la dueña. Esto nos pone ante la aceptación de la cantina como prolongación del espacio doméstico, que sería el espacio de la mujer "decente", pero a la vez como espacio en el que como dice un dicho popular las mujeres decentes no deben entrar, mucho menos trabajar en él. 
Contradictoriamente, y a pesar de que en el imaginario de "lo que debe ser" la cantina aparece como un lugar no apropiado para las mujeres, cuando se habla de las dueñas de las cantinas siempre se las admira por salir adelante gracias a su trabajo (negocio), por mantener a sus hijos y por poder lidiar con los borrachos. La opinión que tienen hombres y mujeres sobre las dueñas de las cantinas es de mujeres luchonas, de mujeres que hacen su lucha (por ellas y sobre todo por sus hijos):

Que son más libres. iDicen que ellas se dan a valer! Los hombres las ven bien, porque ellas no dependen de nadie, ellas demuestran, y es verdad, que ino necesitan de ningún hombre para salir adelante! por el trabajo o por lo que sean, porque iellas luchan! (Carlos).

Este argumento de no depender de los hombres (de nuevo autonomía y poder frente a otras mujeres y frente a los hombres), de no querer que ningún hombre las mande y de querer divertirse es muy recurrente en los discursos de mujeres que decidieron quedarse "solas", como es el caso de la mayoría de las cantineras. Muchas de estas cantineras, que en su juventud viajaron, trabajando en diferentes lugares, divirtiéndose (como dicen ellas para referirse a que nadie las controló), siendo independientes y autosuficientes, son las que más tarde decidieron poner una cantina, son las dueñas de las cantinas, o si no son dueñas son las regentes, es decir el lugar es propiedad de otra persona pero ellas se lo rentan. 
De este modo la dueña de la cantina se convierte en la autoridad femenina de un espacio privado pero con uso público y ocupado por hombres, lo cual hace que ese lugar se masculinice en determinados momentos del día, pero incluso en estos momentos el "poder" y la "autoridad" la tiene estas mujeres:

Pues fíjate, yo desde que empecé, tengo tres años trabajando yo así con cerveza, nunca se han agarrado, porque yo cuando quiera ¿sabé que? ibájese!... isoy groseraa! isáquense a la verga! les saco... les vacío toda la cerveza y órale... y me hago respetar, fíjate que me ha costado de que, ide ganarme el respeto! Cómo yo le digo el respeto no se compra, iese se gana! Y yo icuántos años!... a mi itodos me respetan aquí! No porque yo venda una... ino, no! que digan ipinche! ya sabes cómo es el de la costa de malhablado y iaquí no! A mí me han respetado. Ya que están borrachos los saco, isíí! no se haga una agarrasón y los saco... y ise van!... no, no, manita, mis respetos y se van (Dueña de cantina).

Cuestiono así la imagen social que se tiene de la cantina como un lugar únicamente público y masculino. Pretendo mostrar la figura de la dueña de la cantina como mujer "dueña" de un lugar femenino masculinizado y a la vez espacio masculino feminizado. 


\section{Para finalizar}

Pero, iquiénes son las mujeres de las que se habla en este texto?, son mujeres que yo denomino como "solas": solteras, fracasadas y queridas. Es decir mujeres que se salen de la "norma" en cuanto que no responden al modelo ideal de mujer casada que vive con un hombre y tiene hijos, sino que por unas circunstancias u otras son cabeza de familia y hacen su lucha para mantenerse a sí mismas y a sus familias. Estas mujeres marcan una ruptura (a través de sus prácticas y acciones cotidianas) con la normalidad de ser mujer, con la normatividad impuesta, ya que lideran prácticamente todos los eventos rituales, tanto civiles como religiosos, trabajan tanto en el ámbito reproductivo-doméstico, como en el productivo y adoptan estrategias de supervivencia, que se convierten en un potencial de autonomía económica y gestión sobre sus propios cuerpos (algo que normalmente ha sido controlado por "otros") al margen del control de los hombres. Esta ruptura pasa por la ocupación de prácticamente todos los espacios y de la presencia en las actividades productivas, feminizando tanto unos, como otras.

A partir de estas prácticas, analizo la dialéctica que se establece entre poder y resistencia. Me interesan las formas de resistencia que implican algunas actitudes y actividades cotidianas, no las organizadas política y militarmente. Las formas de poder y resistencia cotidianas son difíciles de observar y analizar, ya que suelen estar enmascaradas en otras concepciones y actividades, que pasan desapercibidas. 
En este texto me he centrado en dos de los aspectos, que considero básicos y más importantes para resistir a este poder y control masculino, como son la ocupación y feminización de espacios, en un principio, considerados masculinos, y la creación de redes de solidaridad y ayuda mutua entre las mujeres, a partir del ejercicio de actividades productivas, lo cual representa una resistencia al aislamiento y "domesticación" de estas.

Tras comenzar con algunos aportes teóricos sobre la construcción genérica del espacio y la organización de este a través de prohibiciones y normas, nos hemos adentrado en el día a día de un pueblo de la Costa Chica, en su cotidianidad, marcada por los tiempos y los espacios, tanto femeninos como masculinos para de este modo ver la relación entre ideología y práctica espacial. Es decir aunque en los discursos, en las conversaciones se haga alusión al lugar que le corresponde a hombres y mujeres y se estigmatice, sobre todo, que las mujeres ocupen los espacios masculinos, en la práctica vemos que apenas hay espacios propiamente masculinos, ya que siendo éste el público, según la ideología comunitaria, las mujeres se apropian continuamente de él y lo resignifican a partir de sus prácticas y tiempos. Esto también lo vemos con el espacio doméstico, que adopta un significado y un estatus público a partir de las prácticas femeninas. Por tanto, debemos prestar mucha atención a la dialéctica que se establece entre prácticas y discursos. Debemos hacer hincapié en las prácticas, las cuales siguen lógicas distintas a las del discurso. Lógicas que parten, como veíamos, del concepto de "necesidad" y adaptación. 
Para poder ver este juego entre discurso y práctica y las verdaderas dinámicas que se dan entre hombres y mujeres es necesario incorporar la perspectiva de género, sin la cual no podremos darnos cuenta de cómo se viven diferencialmente (para hombres y para mujeres) los espacios, qué significado tiene, para unas y otros, un mismo lugar y cómo se relacionan en él. Los mismos espacios pueden tener significados diferentes para las mujeres y para los hombres, viviéndolos y conceptualizándolos de modo diferente, pudiendo llevar incluso a conflictos por el diferente significado o por el diferente aporte que le dan unos y otras.

El pulso entre ideología y práctica espacial tiene muchos limitantes, ya que en una economía rural, bastante limitada a la producción de papaya y en la que no existen muchos recursos más de subsistencia, aparte de emigrar, la mujer no puede limitarse a un ámbito privado y limitar su actividad al ámbito reproductivo. En este sentido, las mujeres de la costa son protagonistas activas de la política y la economía comunitaria, son el "motor" que permite que las relaciones sociopolíticas y culturales marchen. Algo que se acentúa cuando vemos la cantidad de mujeres "solas" que hay en el pueblo y cómo estas "hacen su lucha" y encuentran cómo "hacerle sin un hombre".

Como reflexión final introduzco una nueva vertiente que se desprende de esta investigación y que se refiere a los cambios que se están dando, en los últimos años, en relación a la presencia de las mujeres en los espacios comunitarios. Las parejas jóvenes (sobre todo las chicas, que opinan que así son más independientes y no tienen que lidiar con suegras y nueras) prefieren no convivir con 
las familias y optan por residencias neolocales. Esto aumenta el aislamiento que sufre la mujer en el ámbito doméstico, ya que al contrario de sus madres y abuelas, estas chicas no suelen trabajar fuera del ámbito doméstico, lo que dificulta la creación de redes de solidaridad femenina y ayuda mutua entre las jóvenes, a lo que se suman los impedimentos por parte de los hombres para que sean autosuficientes y autónomas económicamente. El hombre asume su rol de proveedor, lo que coloca a las mujeres en una posición de dependencia total. Otras veces, si el marido se encuentra en el norte, la mujer suele permanecer con la familia de él, lo que conlleva una gran pérdida de independencia y un control sobre todos sus movimientos. Esto sumado a las nuevas tendencias de consumo capitalista (en una realidad económica de subsistencia y precariedad) que hace que los jóvenes hayan crecido en una cultura del gasto, y del consumo de artículos de moda y belleza, en la que todo cuesta dinero, provoca un aumento de la dependencia de las mujeres hacia los hombres, y del poder de estos, al ser ellos los que deciden si les proporcionan estos artículos o no.

Ante estas nuevas formas de control y poder sobre las mujeres, habrá que ver cuáles son las formas de resistencia que construyen y adoptan estas "nuevas" mujeres.

\section{Bibliografía}

AlbORCH, C. Malas (2002). Rivalidad y complicidad entre mujeres. Madrid:

El País Aguilar. 
BAstos, Santiago (1997). "Desbordando patrones: el comportamiento doméstico de los hombres”, La Ventana, Núm. 6, 1997, pp: 164-222.

— (2000). "Cultura, pobreza y diferencia étnica en ciudad de Guatemala", Tesis Doctoral, Centro de Investigaciones y Estudios Superiores en Antropología Social de México.

Bourdieu, Pierre (2000). La dominación masculina. Barcelona: Anagrama.

—— y WACQUANT, Loïc J. D. (1995). Por una antropología reflexiva. México: Grijalbo.

CAso, Alfonso (1996). Reyes y Reinos de la Mixteca. México: FCE.

Córdova, Rosío (2003). Los peligros del cuerpo: género y sexualidad en el centro de Veracruz". México: Plaza y Valdés.

Chávez Arellano, María Eugenia; Verónica VÁzQuez García, y Aurelia De la Rosa Regalado (2007). "El chisme y las representaciones sociales de género y sexualidad en estudiantes adolescentes." Perfiles educativos, Núm. 115, Vol. 29, pp: 21-48.

De BARbieri, Teresita (1991). "Los ámbitos de acción de las mujeres", Revista Mexicana de Sociología, Núm. 1, Vol. 53, Universidad Nacional Autónoma de México, pp: 203-224.

SEsia, Paola María (2011). Diagnóstico de la situación de las mujeres afrodescendientes en la Costa Chica. Oaxaca: CIESAS-Pacífico Sur.

FoucAult, Michel (1992). El orden del discurso. Buenos Aires: Tusquets Editores.

HARris, Olivia (1986). "La unidad doméstica como unidad natural", Nueva Antropología, Núm. 30, Vol. VIII, México, pp. 199-222. 
hooks, bell (2004). "Mujeres negras. Dar forma a la teoría feminista", en hooks, b.; Brah, A.; Sandoval, C.; Anzaldúa, G., Otras inapropiables. Feminismos desde las fronteras, Traficantes de sueños. Madrid, pp. 33-51. Juliano, Dolores (1998). Las que saben. Subculturas de mujeres. Madrid: Horas y Horas.

Loayza Castro, Natasha (1997) El trabajo de las mujeres en el mundo global, paradojas y promesas. La Paz: Centro de promoción de la mujer Gregoria Apaza.

MACGAFFEY, Janet (1986). "Women and class formation in a dependent economy: Kinsagany entrepreneurs", en Robertson C. y Berger I., Women and Class in Africas, Africana Publishing Company, Nueva York, pp. 161-77.

Masferrer León, Cristina Verónica (2014). “Aquí antes se llamaba Poza Verde. Conocimientos de niños de la Costa Chica sobre su pueblo y lo negro", Tesis de Maestría en Antropología Social, Centro de Investigaciones y Estudios Superiores en Antropología Social.

Meillassoux, Claude (1999) Mujeres, graneros y capitales. México: Siglo XXI.

Miranda Reyes, Mariana (2012). "Soy la negra de la costa. La reconfiguración de la identidad de género de mujeres afromexicanas de la Costa Chica", Tesis de Maestría en Ciencias Sociales, Facultad Latinoamericana de Ciencias Sociales, Sede Académica México. Moore, Henrietta L. (1999). Antropología y Feminismo. Madrid: Cátedra. NAROtZKY, Susana (2004). Antropología económica. Nuevas tendencias. España: Melusina. 
Quiroz MalcA, Haydee Clotilde (1998). "Las mujeres y los hombres de sal. Un proceso de producción y reproducción cultural en la costa chica de guerrero", Tesis de Doctorado, Universidad Iberoamericana. Rodríguez Cabrera, Verónica y Quintana, Roberto Diego (2002). "Paradojas Conceptuales del Género en Procesos de Cambio de Mujeres Indígenas y Campesinas en el México Rural”, Cinta de Moebio, №. 13,Universidad de Chile, 2002. Recuperado de <http:// www.redalyc.org/articulo.oa? id $=10101313>$

RosAlDO, Michelle (1979) "Mujer, cultura y sociedad: una visión teórica”, en Harris, O. y Kate, Y. Antropología y feminismo. Barcelona: Editorial Anagrama, pp. 153-181.

SÁNCHEZ PÉrez, Francisco (1990). La liturgia del espacio. Antropología de la arquitectura y el género. Madrid: Ed. Nerea - Departamento de Antropología Social. Facultad de Ciencias Políticas y Sociología, Universidad Complutense de Madrid. Recuperado de biblioteca.ucm.es/escritores/ francisco_sanchez/obras/obr1306.pdf.

Soto Villagrán, Paula (2003). "Sobre género y espacio", Revista GénEros, Núm. 31, Año 11, Universidad de Colima, pp. 88-93

STACK, Carol B. (1975) All our kin. Basic Books.

Viveros Vigoya, Mara (2002). De quebradores y cumplidores: sobre hombres, masculinidades y relaciones de género en Colombia. Colombia: Ces, Universidad Nacional de Colombia- Fundación Ford- Profamilia. 